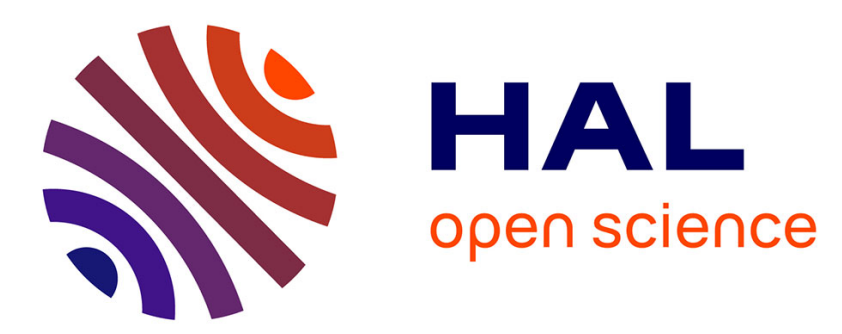

\title{
Temperature dependence of xenon excimer formations using two-photon absorption laser-induced fluorescence
}

Frédéric Marchal, Neermalsing Sewraj, G Jabbour, P Rodriguez Akerreta, G. Ledru

\section{- To cite this version:}

Frédéric Marchal, Neermalsing Sewraj, G Jabbour, P Rodriguez Akerreta, G. Ledru. Temperature dependence of xenon excimer formations using two-photon absorption laser-induced fluorescence. Journal of Physics B: Atomic, Molecular and Optical Physics, 2010, 43 (23), pp.235210. 10.1088/09534075/43/23/235210 . hal-00576260

\section{HAL Id: hal-00576260 https://hal.science/hal-00576260}

Submitted on 14 Mar 2011

HAL is a multi-disciplinary open access archive for the deposit and dissemination of scientific research documents, whether they are published or not. The documents may come from teaching and research institutions in France or abroad, or from public or private research centers.
L'archive ouverte pluridisciplinaire HAL, est destinée au dépôt et à la diffusion de documents scientifiques de niveau recherche, publiés ou non, émanant des établissements d'enseignement et de recherche français ou étrangers, des laboratoires publics ou privés. 


\title{
Temperature dependence of xenon excimer formations using two photon absorption laser induced fluorescence.
}

\author{
F Marchal, N Sewraj, G Jabbour, P Rodriguez Akerreta and \\ G Ledru
}

Université de Toulouse; UPS, INPT; LAPLACE (Laboratoire Plasma et Conversion d'Energie);118 route de Narbonne, F-31062 Toulouse Cedex 9, France.

E-mail: frederic.marchal@laplace.univ-tlse.fr

\begin{abstract}
The temporal dependence of VUV emissions of the first continuum of xenon at around $150 \mathrm{~nm}$ are investigated for pressures ranging from 10 to 100 Torr and for temperatures ranging from 200 to $300 \mathrm{~K}$, after briefly and selectively populating exclusively the resonant or the metastable atomic states of the $5 \mathrm{p}^{5} 6 \mathrm{~s}$ configuration. A kinetic and spectroscopic study was performed by analyzing the VUV post luminescence decay of xenon operating with such excitation conditions. Our results clearly show the temperature effects on the rate constants $\alpha_{31}$ and $\alpha_{32}$ of formation of excimers correlated respectively to the first resonant and the first metastable states by three-body collisions. The resulting reaction rates are obtained as a function of temperature $T: \alpha_{31}=3.90 \times 10^{-27} T^{-1.78} \mathrm{~cm}^{-6} \mathrm{~s}^{-1}$, $\alpha_{32}=1.34 \times 10^{-27} T^{-1.70} \mathrm{~cm}^{-6} \mathrm{~s}^{-1}$. For the whole pressure range, low temperatures favour the formation of xenon excimers and the efficiency of the three-body collisions in forming stabilized excimers increases with decreasing temperature
\end{abstract}

PACS numbers: 32.30.Jc, 32.80.Rm, 32.80.Wr, 33.20.-t, 33.80.-b, 52.20.-j, 52.25.b, 52.25.Ya, 52.38.-r, 52.70.kz, 52.80.s

Submitted to: J. Phys. B: At. Mol. Phys. 


\section{Introduction}

Xenon excilamps, also called xenon excimer lamps, emit VUV radiation with high efficiency [1-3]. Rare-gas based excilamps are used for applications in photochemistry, photobiology, surface treatment, mercury-free lamps and photochemical technology [412]. These applications often concern dielectric barrier excimer lamps. Optimization of these VUV sources requires numerical modeling associated with experimental characterization. Recently, a study of xenon VUV emissions in a mono-filamentary dielectric barrier discharge was carried out by our team [3]. The measured DBD VUV efficiency of a single xenon micro-discharge reported in this paper was independent of frequency and ranged between $55 \%$ and $60 \%$, and the maximum value was reached for 200 Torr.

The emission mechanisms of VUV radiations by rare gases are now reasonably understood. Excimers correlated to the first metastable or resonant states are responsible of these emissions. In some previous papers [13-17], we have determined kinetic models of formation and decay of rare gases excimers in the case of argon, krypton, xenon and krypton-xenon mixtures. We have established that kinetic studies under brief and selective excitation conditions are highly suitable for the determination of reliable kinetic models. Moutard et al [18] reported that non-selective excitation techniques are not clean methods for the determination of kinetic models for excimer formation and decay because several processes compete (ionization, electron-ion recombination, electron-ion formation and destruction, second-electron kinetics, etc).

The first metastable state Xe6s $[3 / 2]_{2}^{0}$ and the first resonant one Xe6s $[3 / 2]_{1}^{0}$ are the precursors to the excimer states $\mathrm{Xe}_{2}^{*}$. Three-body collisional processes lead to the formation of the high vibrational levels of these excimers. The transition of these high vibrational levels correlated to the lowest atomic excited states towards the weakly bound ground-state dimers leads to the emission of the first continuum of xenon at wavelengths around $150 \mathrm{~nm}$. The second continuum is observed at high pressures when relaxation of the high vibrational levels of these excimers is most likely. Thus the second continuum, arising from radiative transitions of the lowest vibrational levels of the molecular excited states towards the ground state, dominates the spectrum. The three-body rate constants of excimer formation were estimated at room temperature and our values are in good agreement with those reported by many other authors using different excitation methods: laser induced fluorescence, pulsed gas-discharges, electron-beam excitation, $\alpha$-particles, synchrotron radiation $[3,14,17,19-24]$. However, except the works of Turner [25] in krypton afterglow and Wieme and Lenaerts [26] in argon, krypton and xenon afterglows, not much attention was paid to the temperature dependence of these three-body rate constants. In these two latter works, the excitation technique was not selective and the kinetic models describing the formation and decay of the lowest xenon excimers do not agree with those proposed using selective excitation methods $[14,22,24,27]$.

In this paper, we present an experimental spectroscopic and kinetic analysis, using 
two-photon laser induced fluorescence technique (TALIF), in order to evaluate the temperature influence on the emission of the first continuum of xenon. With this technique, the first metastable state Xe $6 \mathrm{~s}[3 / 2]_{2}^{o}$ or the first resonant one Xe $6 \mathrm{~s}[3 / 2]_{1}^{o}$ could be selectively populated after a brief $(7 \mathrm{~ns})$ laser pulse. These states are precursors to the excimer states responsible of VUV emissions. For pressures lower than 100 Torr, we analyzed the time-dependence of the VUV emissions of the first continuum, for gas temperatures lying between $200 \mathrm{~K}$ and $300 \mathrm{~K}$, in order to estimate the temperature dependence of the observed decay frequencies. The evolutions of these decay frequencies with both the pressure and temperature allowed us to determine the effect of the temperature on the reaction rate constants of excimer formation.

\section{Experimental methods}

The schematic diagram of our experimental setup used for TALIF is shown in figure 1. The YAG laser (Spectra-Physics) delivered $7 \mathrm{~ns}$ wide pulses with a repetition rate of $30 \mathrm{~Hz}$ which pumped a Sirah dye laser using Rhodamine 6G. The spectral width of $0.002 \mathrm{~nm}$ was obtained with a 1800 grooves $/ \mathrm{mm}$ double grating. The frequency of the

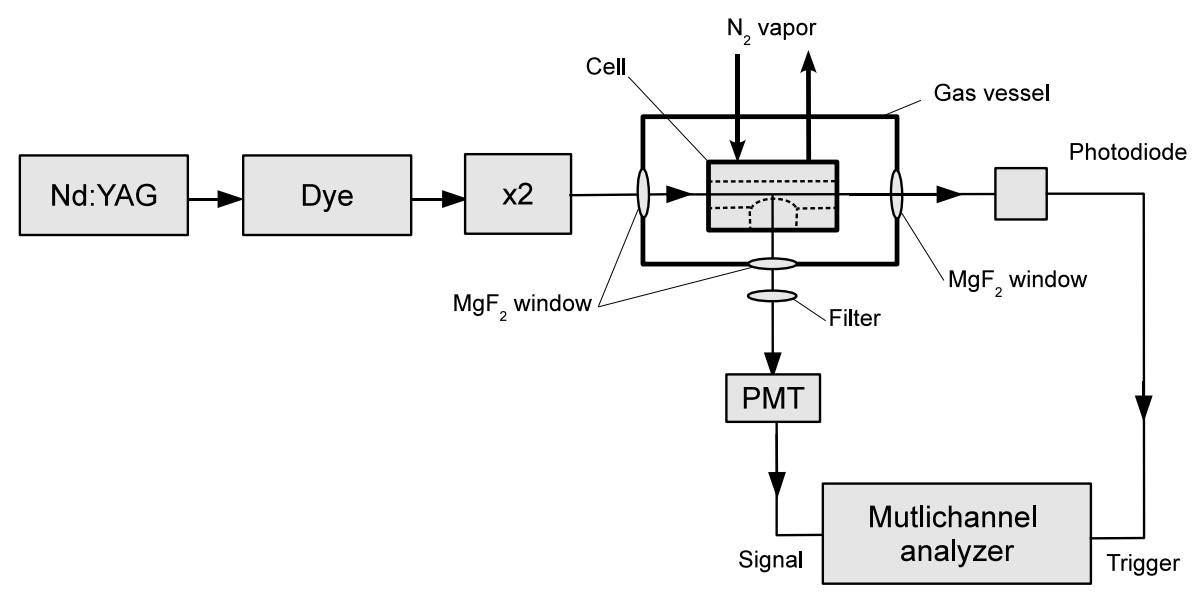

Figure 1. Schematic diagram of the T.A.L.I.F. experimental-setup, the vacuum system is not represented.

laser beam, was doubled by a KDP crystal and entered, without focusing, a stainlesssteel cell filled with the working gas and cooled by circulation of saturated nitrogen vapor. The cell was enclosed by a windowed cylindrical vessel. The UV energy of the frequency-doubled light was approximately $1 \mathrm{~mJ}$. Two-photon excitation was achieved by the laser beam along the cell axis and the fluorescence of the gas in the interaction volume was observed perpendicularly to the laser beam. The VUV fluorescence was monitored through a $\mathrm{MgF}_{2}$ window by a VUV photomultiplier tube (PMT: EMR-510G extremely solar blind) operating in the single photon counting mode. The emission wavelengths were selected by respectively, a VUV Mc Pherson 218 monochromator for the recording of the emission spectra, and an interferential filter centred at $145 \mathrm{~nm}$ 
$(\mathrm{FWHM}=17.5 \mathrm{~nm})$ or $168 \mathrm{~nm}(\mathrm{FWHM}=10.5 \mathrm{~nm})$ for both the excitation spectra and the time-dependence studies. The VUV luminescence was recorded using a multichannel analyzer (Stanford Research SR430) operating with 16384 channels and a time resolution of $5 \mathrm{~ns}$.

The temperature of the cell was monitored using thermocouples fixed to the cell's envelope. The differences between gas temperature in the interaction volume and the wall temperature was measured in order to determine the temperature bias. Our calculations done when modelling heat exchange with FLUENT software, show that the temperature inside the interaction volume is uniform within a maximum interval of $\pm 2 \mathrm{~K}$. Fluorescence measurements were performed at stable temperatures ranging from $193 \mathrm{~K}$ to room temperature when the pressure remained constant and uniform in the small interaction volume at the center of the cell.

TThe vessel was filled with laboratory-grade pure xenon (Air Liquide, 99.9996\% purity). Before filling, the cell was pumped down to a residual pressure of less than $10^{-7}$ Torr. For further purification, during filling up, the gas was drifted through an aluminium-zirconium getter pump. The UV laser beam energy at the exit of the vessel was measured and controlled to avoid multiphotonic ionization.

The experimental histograms recorded at $\sim 145 \mathrm{~nm}(\Delta \lambda=17,5 \mathrm{~nm})$ representative of the fluorescence decay of the first continuum of xenon, are characterized by a large number of $N_{C}$ channels and a low counting rate per channel width, $\Delta t=5 \mathrm{~ns}$. The time function of the fluorescence decay was fitted by a function $f(t)$ which maximizes the likelihood function, assuming a Poisson distribution of our photon counts. This method is suitable for the low counting rates encountered in our experiments because it yields more accurate estimations of decay frequencies $[13,28]$. The modelling of the fluorescence decay of excited species by the function $f(t)$ determined the rate equation model of collisional and radiative decay in a pure neutral gas. In our experimental excitation conditions, the number density of excited species in the interaction volume remained weak and the multiphotonic ionization could be neglected. Therefore, collisions between excited species, ionic recombination or electronic collisions were not considered. Thus the function $f(t)$ is given by:

$$
f(t)=\sum_{p=1}^{p=N_{S}} A_{p} \exp \left(-\frac{t}{\tau_{p}}\right)
$$

where $N_{S}$ is the number of excited states involved in the formation-decay processes and $\frac{1}{\tau_{p}}$ is the decay frequency of each state. In pure gas, the decay frequency of the $p$ th term with respect to xenon number density $[\mathrm{Xe}]$ is:

$$
\frac{1}{\tau_{p}}=\alpha_{1 p}+\alpha_{2 p}[\mathrm{Xe}]+\alpha_{3 p}[\mathrm{Xe}]^{2}
$$

where $\alpha_{1 p}$ represents the radiative decay frequency, $\alpha_{2 p}$ the two-body collisional rate constant and $\alpha_{3 p}$ the three-body collisional rate constant.

The radiative and collisional rate constants were obtained by a least square fitting of the experimental measurements of the decay frequencies. Standard uncertainties were 
estimated according to ISO standards [29]. Calculations of the estimated uncertainties are fully described in a previous paper [13]. Our results are all given with their expanded uncertainties $U(\alpha)$ obtained by multiplying the combined standard uncertainty by the coverage factor 2 which defines a confidence level of approximately $95 \%$.

\section{Results}

\subsection{Excitation spectra}

According to the selection rules, only $g$ states can be populated from the molecular ground state by 2-photon absorption excitation process (figure 2). The 2photon transition populating the metastable state is parity forbidden in the dipole approximation but allowed via higher-order multipole contributions [30,31].

In order to perform a kinetic study under selective excitation of the first metastable state Xe $6 \mathrm{~s}[3 / 2]_{2}^{o}$ or the first resonant state Xe $6 \mathrm{~s}[3 / 2]_{1}^{o}$, one has to seek for the laser excitation wavelengths suitable for selectively populating these low-lying excited states. Our incident pulsed UV laser beam is tunable and its energy range allows two-photon excitation of the metastable state Xe $6 \mathrm{~s}[3 / 2]_{2}^{o}$, or both the $1_{g}$ and $2_{g}$ molecular states correlated the first metastable state, as well as both the $0_{g}^{+}$and $1_{g}$ ones correlated to the resonant state $\mathrm{Xe} 6 \mathrm{~s}[3 / 2]_{1}^{o}$.

At low pressures, our excitation spectra were recorded by collecting the photons emitted by the first continuum. For high pressures, those coming from the second continuum were considered. Over the whole pressure range, the same atomic and molecular bands were observed but the intensities were weaker at low pressures. Figure 3 shows the temperature dependence of the excitation spectra recorded at $p_{X e}=200$ Torr between $200 \mathrm{~K}$ and $300 \mathrm{~K}$ for the second continuum emissions at $172 \mathrm{~nm}$.

For all temperatures, a sharp line $(F W H M=0.003 \mathrm{~nm})$ peaking at $298.170 \mathrm{~nm}$ is observed (fig. 3). This atomic excitation line corresponds to the $5 \mathrm{p}^{6}\left({ }^{1} S_{0}\right)-6 \mathrm{~s}[3 / 2]_{2}^{o}$ twophoton transition. The molecular band peaking at $296.4 \mathrm{~nm}$, which was first identified by Gornick et al [30], corresponds to $\mathrm{Xe}_{2}\left(\mathrm{~A} 1_{g}\right)$. The excitation signal is detected on the high energy side of the metastable atomic dissociation limit. According to the potential energy curves calculated by Jonin et al $[32,33]$, the well-depth of the $\mathrm{Xe}_{2}\left(\mathrm{~A} 1_{g}\right)$ state is $180 \mathrm{~cm}^{-1}$ at $R_{e}=4.82 \AA$. Baker's potential curves of the ground state $\mathrm{Xe}_{2}\left(\mathrm{X}_{g}^{+}\right)$show a well-depth of $196 \mathrm{~cm}^{-1}$ at $R_{e}=4.36 \AA$. Therefore, the two-photon excitation can take place in the van der Waals minimum at internuclear distances $R<4.36 \AA$ where the exited $g$ state is essentially repulsive.

The intensity of the molecular absorption structure of $\mathrm{Xe}_{2}\left(\mathrm{~A} 1_{g}\right)$ increases with decreasing gas temperature. The fraction of bound-free pairs increase from $0.14 \%$ at room temperature to $0.4 \%$ at $200 \mathrm{~K}$ for 200 Torr xenon pressure. The increasing dimer concentration strengthens the intensity of the molecular structure. No asymmetric broadening is observed. Hence, according to the $\mathrm{Xe}_{2}\left(\mathrm{~A} 1_{g}\right)$ energy potential curve, we can conclude that 2-photon absorption occurs at internuclear distances close to the 


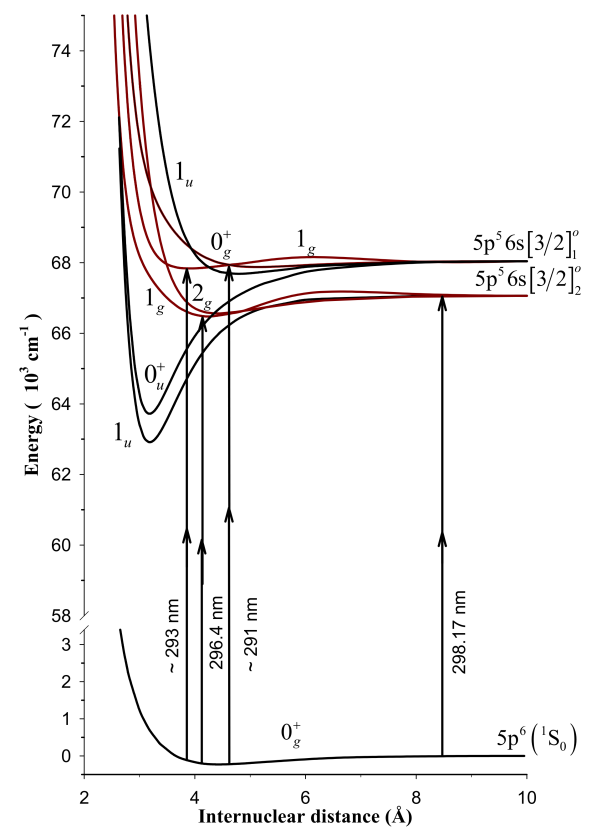

Figure 2. Potentiel curves of the lowest $\mathrm{Xe}_{2}$ electronic states. Two-photon absorption transitions observed are indicated by arrows.

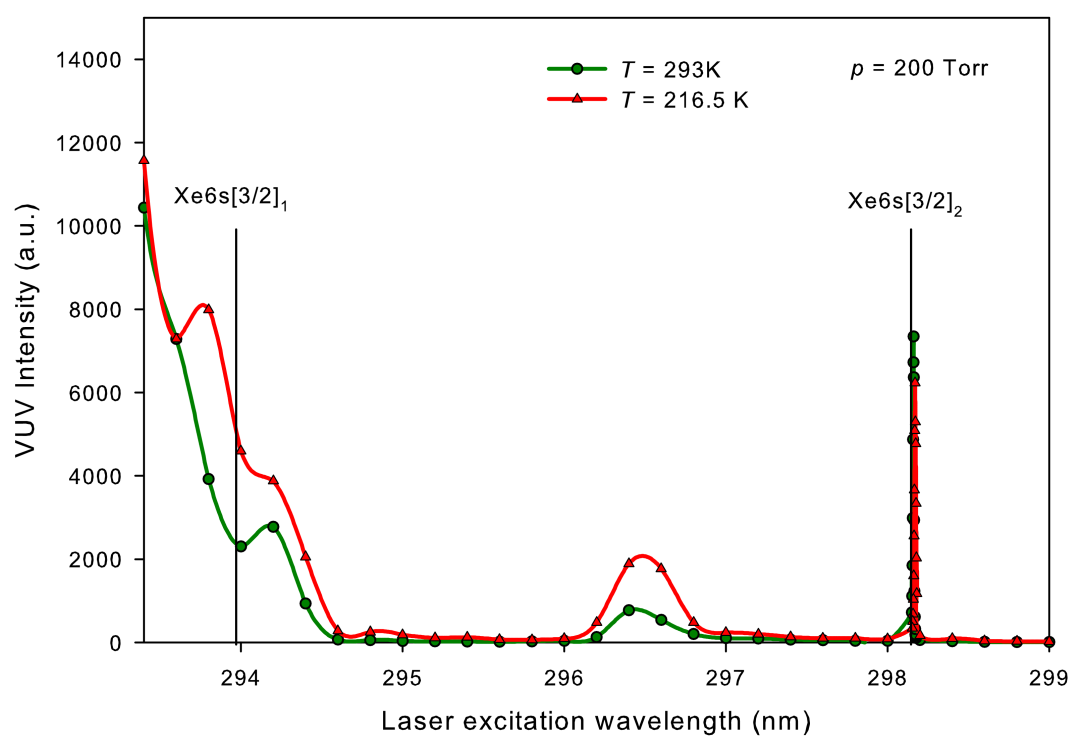

Figure 3. Excitation spectra at $p_{X e}=200$ Torr at room temperature $([\mathrm{Xe}]=$ $\left.6.58 \times 10^{18} \mathrm{~cm}^{-3}\right)$ and low temperature $\left([\mathrm{Xe}]=8.90 \times 10^{18} \mathrm{~cm}^{-3}\right)$. Luminescence of the second continuum $\left(\lambda_{\text {filter }}=168 \mathrm{~nm}, \mathrm{FWHM}=17.5 \mathrm{~nm}\right.$. The positions of the excited Xe $6 \mathrm{~s}[3 / 2]_{2}^{o}$ and Xe $6 \mathrm{~s}[3 / 2]_{1}^{o}$ atomic states are indicated.

bound length of the ground state.

At shorter wavelengths, a 2-photon absorption signal is observed below 295 Torr on the low energy side of the Xe $6 \mathrm{~s}[3 / 2]_{1}^{o}$ dissociation limit. This molecular absorption 
structure corresponds to the excitation spectrum of $\mathrm{Xe}_{2}\left(\mathrm{~B} 1_{g}\right)$ with a probable overlapping of emissions from $\mathrm{Xe}_{2}\left(\mathrm{~B}_{g}^{+}\right)$which can also be excited. The potential

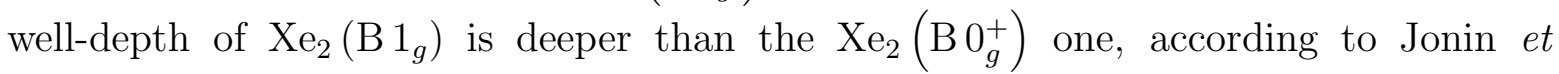
al $[32,33]\left(561 \mathrm{~cm}^{-1}\right.$ at $R_{e}=4.72 \AA$ vs $425 \mathrm{~cm}^{-1}$ at $R_{e}=5.02 \AA$. The intensity of the molecular signal is expected to vanish at internuclear distance close to the dissociation limit because the 2-photon excitation of the resonant state is forbidden. No significant broadening towards the low energy side is observed at low temperatures. Hence at $294 \mathrm{~K}$, the molecular structure for wavelengths below the resonant state can be attributed to $\mathrm{Xe}_{2}\left(\mathrm{~B} 1_{g}\right)$, and absorption arises in the repulsive part of the ground-state potential (e. g. $R \sim 3.9 \AA)$. Excitation of $\mathrm{Xe}_{2}\left(\mathrm{~B}_{g}^{+}\right)$occurs at shorter wavelengths with a maximum around $290.2 \mathrm{~nm}$ according to Ledru et al [14] and Gornik et al [30].

\subsection{Emission spectra}

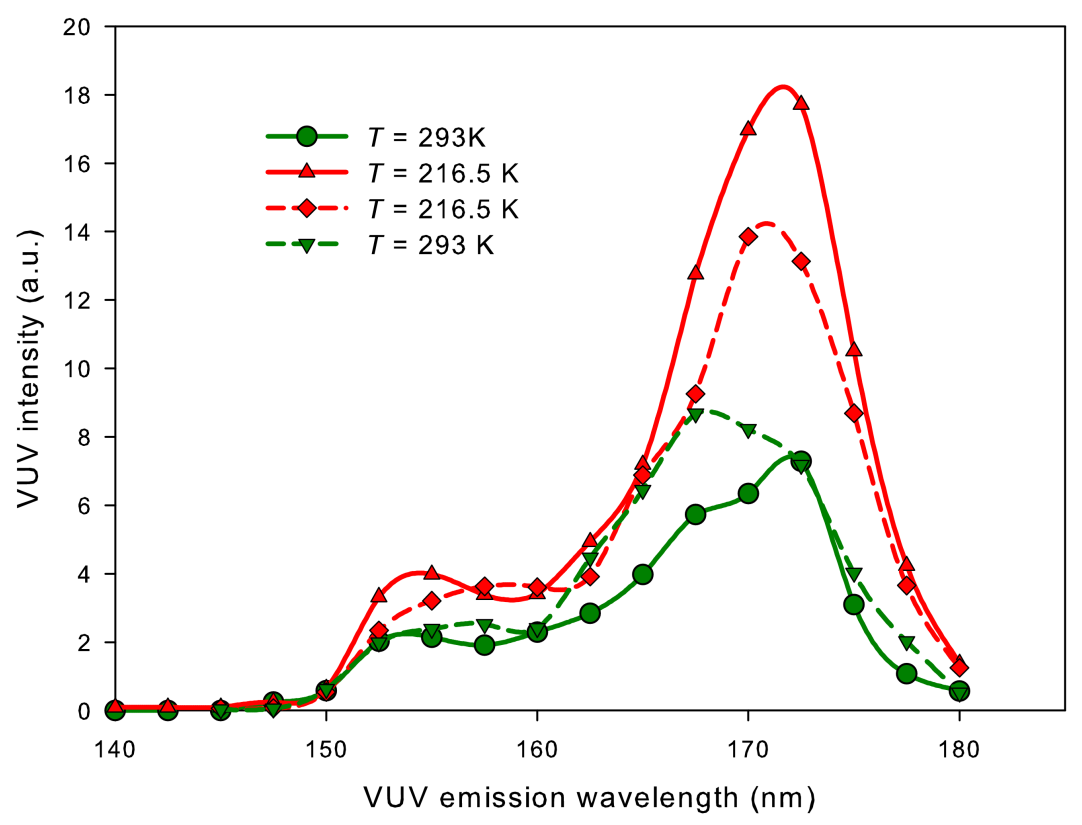

Figure 4. Emission spectra at $p_{X e}=200$ Torr at room temperature $([\mathrm{Xe}]=$ $\left.6.58 \times 10^{18} \mathrm{~cm}^{-3}\right)$ and low temperature $\left([\mathrm{Xe}]=8.90 \times 10^{18} \mathrm{~cm}^{-3}\right)$ following selectively populating the resonant or the metastable states (full lines: excitation $\mathrm{Xe}_{2}\left(\mathrm{~B} 1_{g}\right)$ and dashed lines: excitation Xe $\left.6 \mathrm{~s}[3 / 2]_{2}^{o}\right) . \Delta \lambda=5 \mathrm{~nm}$.

Emission spectra in the $140-180 \mathrm{~nm}$ VUV range were recorded from room temperature down to $200 \mathrm{~K}$ and for low $\left(p_{X e}=50\right.$ Torr $)$ and high $\left(p_{X e}=200\right.$ Torr $)$ pressures following selective excitation of the Xe $6 \mathrm{~s}[3 / 2]_{2}^{o}$ metastable state or the slightly bound molecular state $\mathrm{Xe}_{2}\left(\mathrm{~B} 1_{g}\right)$ on the high energy side of the $\mathrm{Xe} 6 \mathrm{~s}[3 / 2]_{1}^{o}$ dissociation limit. For the second case, the dissociation of the molecular state correlated to the resonant state quickly populates Xe $6 \mathrm{~s}[3 / 2]_{1}^{o}$ atomic state. 


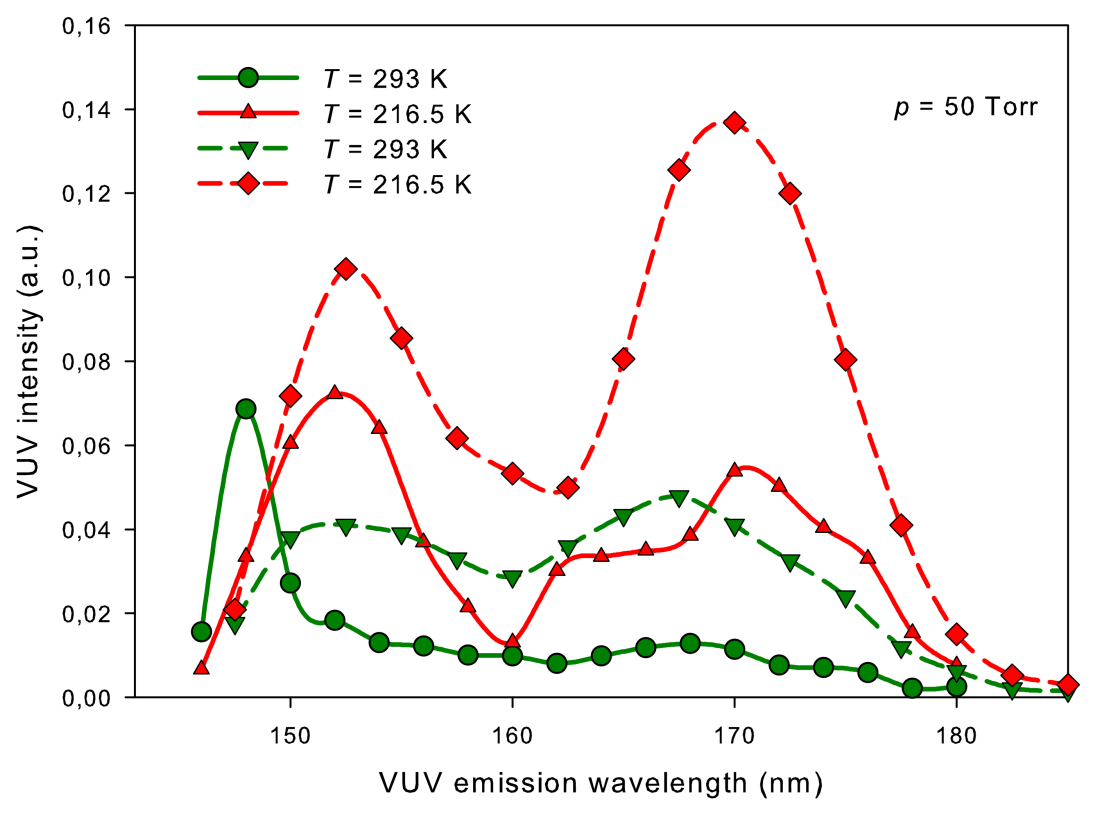

Figure 5. Emission spectra at $p_{X e}=50$ Torr at room temperature $([\mathrm{Xe}]=$ $\left.1.64 \times 10^{18} \mathrm{~cm}^{-3}\right)$ and low temperature $\left([\mathrm{Xe}]=2.22 \times 10^{18} \mathrm{~cm}^{-3}\right)$ following selectively populating the resonant or the metastable states (full lines: excitation $\mathrm{Xe}_{2}\left(\mathrm{~B} 1_{g}\right)$ and dash lines: excitation Xe $\left.6 \mathrm{~s}[3 / 2]_{2}^{o}\right) . \Delta \lambda=5 \mathrm{~nm}$.

At high pressures, particularly above 100 Torr, for either any excitation condition or any gas temperature, the shapes of emission spectra are similar (fig 4). The main emission corresponds to the second continuum peaking at $170 \mathrm{~nm}$. The VUV emission most likely arises from the low vibrational levels of the $\mathrm{Xe}_{2}\left(\mathrm{~A} 1_{u}\right)$ excimer state and, to a much lesser extent from the $\mathrm{Xe}_{2}\left(\mathrm{~B}_{u}^{+}\right)$excimer state. It is observed at low pressures at low temperatures and even at room temperature only when the metastable state is initially excited.

The first continuum which corresponds to transitions from the high vibrational levels of $\mathrm{Xe}_{2}\left(\mathrm{~B}_{u}^{+}\right)$and $\mathrm{Xe}_{2}\left(\mathrm{~A} 1_{u}\right)$, is particularly observed at low pressures ((fig 5$)$, and is nevertheless present at higher pressures, but less weakly (fig 4). Selectively populating either the resonant or the metastable states modifies the shapes of emission spectra. Indeed, when the metastable state is excited, the first continuum peaks at $152 \mathrm{~nm}$ for any temperature. Nevertheless, when the resonant state is initially populated, the first continuum is centered at $147 \mathrm{~nm}$ at room temperature and it gradually shifts towards $152 \mathrm{~nm}$ with decreasing temperature. When the temperature decreases, at low pressures, the emission peaking at $147 \mathrm{~nm}$ is no more observed. The $147 \mathrm{~nm}$ emission arises from the radiative decay of high vibrational levels of the excimer $\mathrm{Xe}_{2}\left(\mathrm{~B}_{u}^{+}\right)$whose lifetime is very short $(\sim 4 \mathrm{~ns}[27])$.

The emission at $152 \mathrm{~nm}$ arises from radiative decay of high vibrational levels of $\mathrm{Xe}_{2}\left(\mathrm{~A} 1_{u}\right)$ state whose lifetimes are longer $(\sim 40 \mathrm{~ns}[34])$. Therefore, after the resonant 
state is populated, an efficient transfer towards the metastable state occurs and the vibrational relaxation of the excimer $\mathrm{Xe}_{2}\left(\mathrm{~A} 1_{u}\right)$ leads to the emission of the second continuum. The emission at $147 \mathrm{~nm}$ arising from the high vibrational levels of the excimer correlated to the resonant state, is not observed following selective excitation of the metastable state. Hence, the reverse transfer from Xe 6s $[3 / 2]_{2}^{o}$ towards Xe 6s $[3 / 2]_{1}^{o}$ is not efficient at all.

The continuous component between $150 \mathrm{~nm}$ and $160 \mathrm{~nm}$ observed at high pressure for any temperature and any excitation corresponds to the radiative transition coming from intermediary vibrational levels of $\mathrm{Xe}_{2}\left(\mathrm{~A} 1_{u}\right)$. The spectra observed at high pressure being similar,suggests that the emissions of the second continuum are most likely due to only one excimer: necessarily $\mathrm{Xe}_{2}\left(\mathrm{~A} 1_{u}\right)$ at low levels of vibrations.

\subsection{Kinetic study}

The temporal analysis of the VUV emissions was performed for pressures between 15 and 100 Torr and in the temperature range of $200 \mathrm{~K}$ to room temperature. The emission wavelengths of the first continuum were selected by an interferential filter centered at $145 \mathrm{~nm}(F W H M=17.5 \mathrm{~nm})$.

The experimental luminescence decays of the first continuum recorded with a time resolution of $5 \mathrm{~ns}$ following initial excitation of either the metastable state or the resonant state are depicted in figures 6 and 7 for two temperatures. The VUV laser induced fluorescence was fit by a sum of exponential terms. Over our whole temperature and pressure ranges, the experimental decay of the first continuum emission is fully described by only one exponential term (decay frequency $\frac{1}{\tau_{2}}$ ) when the metastable state is initially populated. Two exponential terms were required when the $\mathrm{Xe}_{2}\left(\mathrm{~B} 1_{g}\right)$ dissociative state was initially excited. The same decay frequency $\frac{1}{\tau_{2}}$ was found when analyzing the both luminescence decays obtained following the two different excitations:

- following selective excitation of Xe $6 \mathrm{~s}[3 / 2]_{2}^{o}$ :

$$
I_{2}(t)=B_{2} \exp \left(-\frac{t}{\tau_{2}}\right)
$$

- following selective excitation of $\mathrm{Xe}_{2}\left(\mathrm{~B} 1_{g}\right)$ :

$$
I_{1}(t)=A_{1} \exp \left(-\frac{t}{\tau_{1}}\right)+A_{2} \exp \left(-\frac{t}{\tau_{2}}\right)
$$

The variation of the decay frequencies $\frac{1}{\tau_{1}}$ and $\frac{1}{\tau_{2}}$ with xenon number density are reported in figures 8, 9 and 10 for the whole temperature range. The analytic expression of $\frac{1}{\tau_{2}}$, obtained by a least square fit of the experimentally determined decay frequencies, are similar for the both excitations. Variations of $\frac{1}{\tau_{1}}$ and $\frac{1}{\tau_{2}}$ against the number density are parabolic and no significant two-body rate constant was found. For $\frac{1}{\tau_{1}}$, a radiative decay frequency was determined:

$$
\begin{aligned}
& \frac{1}{\tau_{1}}=\alpha_{11}+\alpha_{31}[\mathrm{Xe}]^{2} \\
& \frac{1}{\tau_{2}}=\alpha_{32}[\mathrm{Xe}]^{2}
\end{aligned}
$$




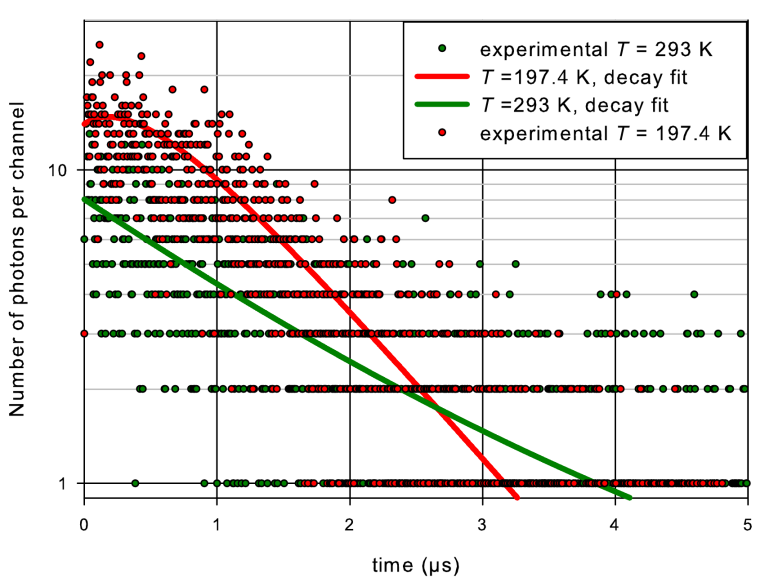

Figure 6. Luminescence decay of the first continuum of xenon at $p_{X e}=50$ Torr at room temperature $\left([\mathrm{Xe}]=1.64 \times 10^{18} \mathrm{~cm}^{-3}\right)$ and low temperature $([\mathrm{Xe}]=$ $\left.2.22 \times 10^{18} \mathrm{~cm}^{-3}\right)$ following selective excitation of $\mathrm{Xe}_{2}\left(\mathrm{~B} 1_{g}\right) . \lambda_{\text {filter }}=148 \mathrm{~nm}$ with $\Delta \lambda=17.5 \mathrm{~nm}$.

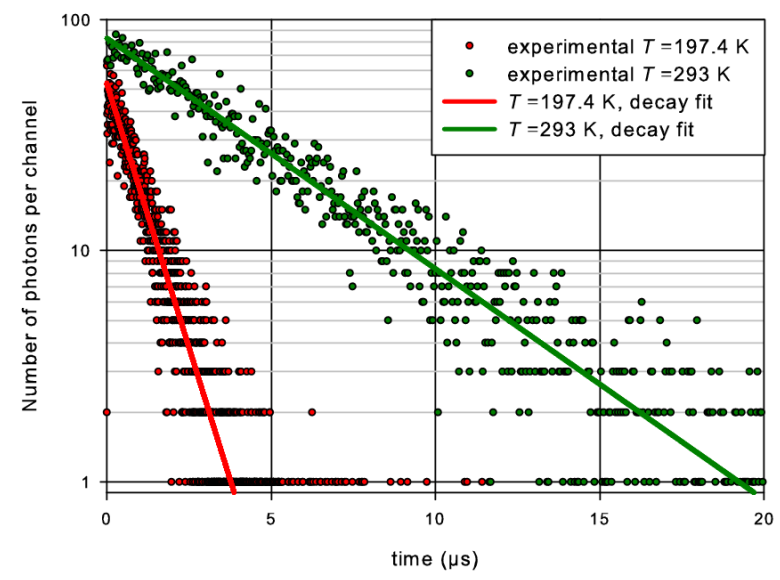

Figure 7. Luminescence decay of the first continuum of xenon at $p_{X e}=50$ Torr at room temperature $\left([\mathrm{Xe}]=1.64 \times 10^{18} \mathrm{~cm}^{-3}\right)$ and low temperature $([\mathrm{Xe}]=$ $2.22 \times 10^{18} \mathrm{~cm}^{-3}$ ) following selective excitation of Xe $6 \mathrm{~s}[3 / 2]_{2}^{o} \cdot \lambda_{\text {filter }}=148 \mathrm{~nm}$ with $\Delta \lambda=17.5 \mathrm{~nm}$.

The experimental values of $\frac{1}{\tau_{2}}$ correspond to the decay of the metastable state by three body-collisions with two ground state xenon atoms.

The parabolic variation of $\frac{1}{\tau_{1}}$ shows that this decay frequency can be attributed to a state which can decays either radiatively or by three-body collisions. The radiative frequency $\alpha_{11}$ represents the apparent lifetime of the resonant state and its value is characteristic of the resonance line trapping phenomenon [17]. The constant $\alpha_{11}$ does not depend on temperature. The experimental value is $\alpha_{11}=(3.27 \pm 0.52) \times 10^{5} \mathrm{~s}^{-1}$.

The experimental kinetic study confirms the spectroscopic observations. So from 


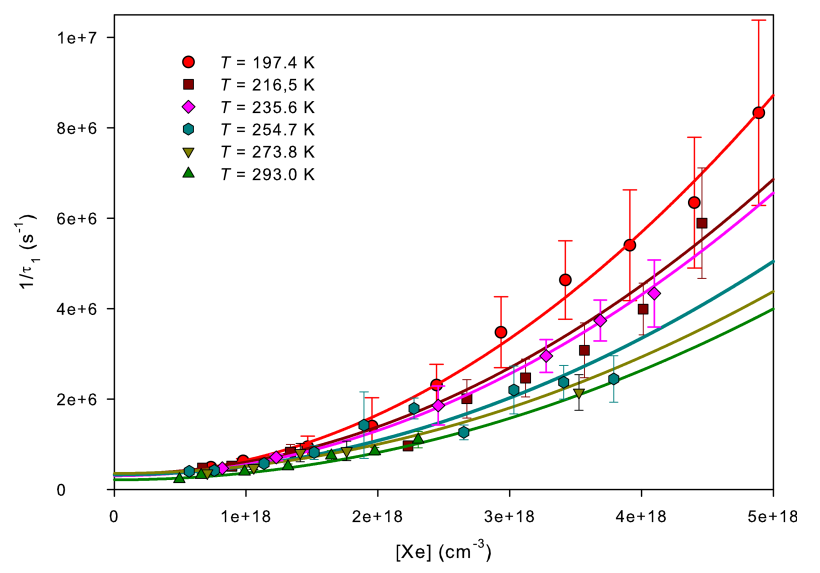

Figure 8. Decay frequency $\frac{1}{\tau_{1}}$ relative to the first continuum of xenon following selective excitation of $\mathrm{Xe}_{2}\left(\mathrm{~B} 1_{g}\right)$. The full lines represent the least square fit of experimental data.

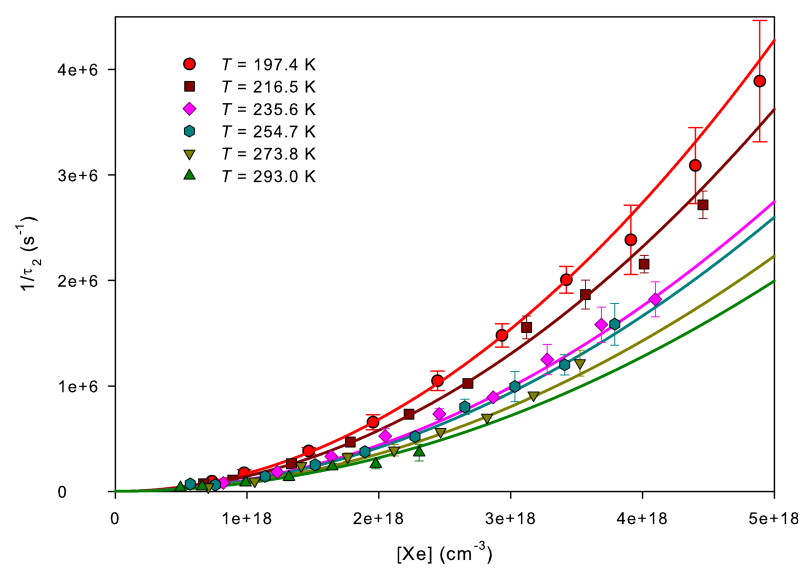

Figure 9. Decay frequency $\frac{1}{\tau_{2}}$ relative to the first continuum of xenon following selective excitation of $\mathrm{Xe}_{2}\left(\mathrm{~B} 1_{g}\right)$. The full lines represent the least square fit of experimental data.

these observations we can conclude that:

- The resonant state decays radiatively or by three-body collision leading to excimer formation;

- The metastable state only decays by three-body collision leading to excimer formation;

- Excitation of the resonant state leads to the population of the metastable state;

- The $\mathrm{Xe}_{2}\left(\mathrm{~B}_{u}^{+}\right)_{v>0}$ can either decay radiatively to form the dissociative molecular ground state or relax via two-body collisions towards the lowest vibrational state. It can also form a repulsive molecular state $\mathrm{Xe}_{2}\left(\mathrm{~A} 2_{u}, 2_{g}, 1_{g}, 0_{g}^{-}\right)$correlated to the metastable state via induced symmetry change collisions. The dissociation of these 


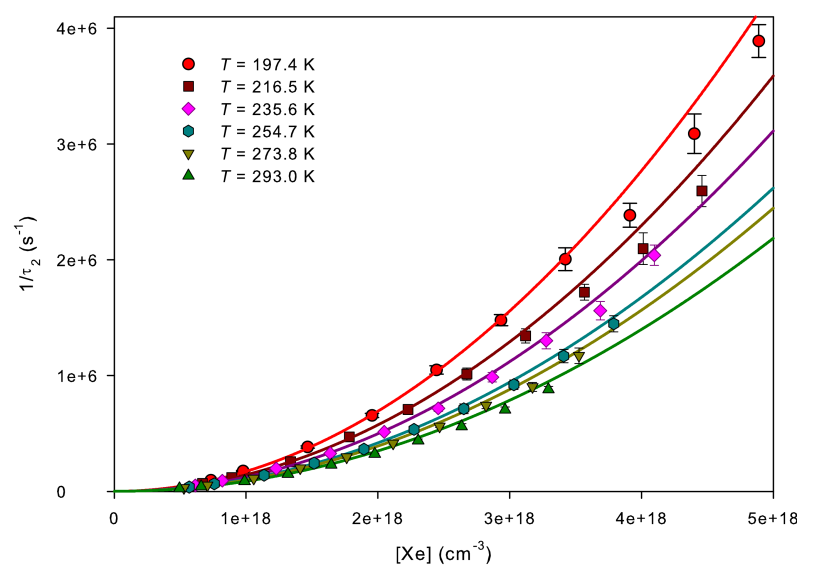

Figure 10. Decay frequency $\frac{1}{\tau_{2}}$ relative to the first continuum of xenon following selective excitation of $\mathrm{Xe} 6 \mathrm{~s}[3 / 2]_{2}^{o}$. The full lines represent the least square fit of experimental data.

repulsive states leads to the metastable state formation. At low temperature, this process seems to be very efficient and the radiative decay of $\mathrm{Xe}_{2}\left(\mathrm{~B}_{u}^{+}\right)_{v>0}$ peaking at $147 \mathrm{~nm}$ is no more observed. On the contrary below 100 Torr, at room temperature, the radiative emission of $\mathrm{Xe}_{2}\left(\mathrm{~B}_{u}^{+}\right)_{v>0}$ peaking at $147 \mathrm{~nm}$ is the main decay process. At room temperature and low pressure, vibrational relaxation and collision induced transfer are not the dominant processes.

- In the whole temperature and pressure range, no transfer or reverse transfer from the atomic resonant state towards the metastable is observed since the analysis of the kinetic decay does not report binary collisions.

- As expected, the Xe 6s $[3 / 2]_{2}^{o}$ atomic state does not decay radiatively but via threebody collisions forming the excimer $\mathrm{Xe}_{2}\left(\mathrm{~A} 1_{u}\right)_{v>0}$. Due to the longer lifetime of the high vibrational levels of this state (about $40 \mathrm{~ns}$ ), the vibrational relaxation of this state competes with the others processes even at low pressure. Therefore the second continuum is also observed at low pressure when the metastable state is initially populated. The maximum of the first continuum is centered at $152 \mathrm{~nm}$. The transition moment of $\mathrm{Xe}_{2}\left(\mathrm{~A}_{u}\right)$ reaches a maximum for an internuclear distance greater than $4 \AA$ and vanishes close to the dissociation limit. This is the reason for which an emission signal is also observed for wavelengths near $160 \mathrm{~nm}$.

- When decreasing the temperature, the three-body collisional rate constants increase. The increase of the decay frequencies can reach one order of magnitude between $300 \mathrm{~K}$ and $200 \mathrm{~K}$.

- The mechanisms involved in the decay of the resonant or metastable state are similar at room temperature and lower ones but the collisional decay frequencies which characterize some of these processes are very sensitive to temperature change. Nevertheless, the relaxation rate constants do not seem to be subjected 
to temperature change because the relative intensities of the first and second continuum are similar at room temperature and lower ones.

\section{Discussion}

The measurements to be discussed were performed in the neutral gas after selectively populating one excited state whose density number is low. The laser beam energy is low enough to avoid multiphotonic ionization. In such conditions, recombination phenomena, electronic collisions or atomic collisions involving two excited species do not contribute to the formation and decay of excimers.

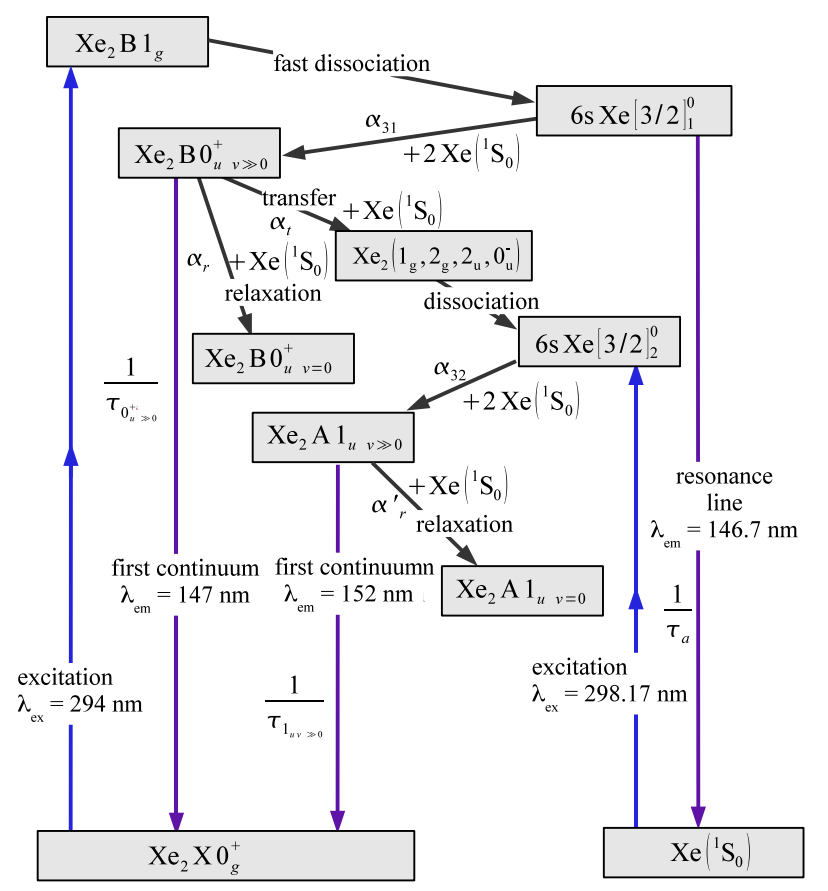

Figure 11. Kinetic scheme indicating the collisional processes and the radiative decays responsible of the the first continuum emissions, involving the metastable state Xe $6 \mathrm{~s}[3 / 2]_{2}^{o}$ and the resonant state Xe $6 \mathrm{~s}[3 / 2]_{1}^{o}$ and the excimer high vibrational levels $\mathrm{Xe}_{2}\left(\mathrm{~A} 1_{u}\right)$ and $\mathrm{Xe}_{2}\left(\mathrm{~B} 0_{u}^{+}\right) . \alpha_{31}$ and $\alpha_{32}$ are the three-body constant rate of formation of excimers.

According to the simplified kinetic scheme established in a previous work at room temperature [14] for the emission of the first continuum, after selectively populating the resonant state, the evolution of the concentration the different states is governed by the differential equations :

$$
\begin{aligned}
& \frac{\mathrm{d}\left[\mathrm{Xe}[3 / 2]_{1}^{o}\right]}{\mathrm{d} t}=-\frac{1}{\tau_{a}}\left[\mathrm{Xe}[3 / 2]_{1}^{o}\right]-\alpha_{31}[\mathrm{Xe}]^{2}\left[\mathrm{Xe}[3 / 2]_{1}^{o}\right] \\
& \frac{\mathrm{d}\left[\mathrm{B} 0_{u v \gg 0}^{+}\right]}{\mathrm{d} t}=-\frac{1}{\tau_{0_{u v \gg 0}^{+}}}\left[\mathrm{B} 0_{u v \gg 0}^{+}\right]-\left(\alpha_{r}+\alpha_{t}\right)[\mathrm{Xe}]\left[\mathrm{B} 0_{u v \gg 0}^{+}\right]+\alpha_{31}[\mathrm{Xe}]^{2}[\mathrm{Xe}[3 / 2(\$))
\end{aligned}
$$




$$
\begin{aligned}
& \frac{\mathrm{d}\left[\mathrm{Xe}[3 / 2]_{2}^{o}\right]}{\mathrm{d} t}=-\alpha_{32}[\mathrm{Xe}]^{2}\left[\mathrm{Xe}[3 / 2]_{2}^{o}\right]+\alpha_{t}[\mathrm{Xe}]\left[\mathrm{B} 0_{u v \gg 0}^{+}\right] \\
& \frac{\mathrm{d}\left[\mathrm{A} 1_{u v \gg 0}\right]}{\mathrm{d} t}=-\frac{1}{\tau_{1_{u v \gg 0}}}\left[\mathrm{~A} 1_{u v \gg 0}\right]-\alpha_{r}[\mathrm{Xe}]\left[\mathrm{A} 1_{u v \gg 0}\right]+\alpha_{32}[\mathrm{Xe}]^{2}\left[\mathrm{Xe}[3 / 2]_{2}^{o}\right]
\end{aligned}
$$

The system describing the decay of the metastable state which is initially selectively excited obeys to the following equations:

$$
\begin{aligned}
& \frac{\mathrm{d}\left[\mathrm{Xe}[3 / 2]_{2}^{o}\right]}{\mathrm{d} t}=-\alpha_{32}[\mathrm{Xe}]^{2}\left[\mathrm{Xe}[3 / 2]_{2}^{o}\right] \\
& \frac{\mathrm{d}\left[\mathrm{A} 1_{u v \gg 0}\right]}{\mathrm{d} t}=-\frac{1}{\tau_{1_{u v} \gg 0}}\left[\mathrm{~A} 1_{u v \gg 0}\right]-\alpha_{r}[\mathrm{Xe}]\left[\mathrm{A}_{u v \gg 0}\right]+\alpha_{32}[\mathrm{Xe}]^{2}\left[\mathrm{Xe}[3 / 2 \mathrm{R}]_{2}\right]
\end{aligned}
$$

The differential equations can be solved to obtain the intensity of the first continuum consecutive to only the decay of the metastable state:

$$
I^{1 s t}(t)=Q \frac{\left[\mathrm{Xe}[3 / 2]_{2}^{o}\right]_{0} \alpha_{32}[\mathrm{Xe}]^{2}}{1+\tau_{1_{u v \gg 0}}\left(\alpha_{r}[\mathrm{Xe}]-\alpha_{32}[\mathrm{Xe}]^{2}\right)}\left[\exp \left(-\alpha_{32}[\mathrm{Xe}]^{2} t\right)+\exp \left(-\left[\frac{1}{\tau_{1_{u v \gg 0}}} \alpha_{r}[\mathrm{Xe}]\right] t\right)\right](
$$

where $Q$ is a constant factor depending on the interaction volume and our VUV detection device.

For the decay of the resonant state initially populated, three components can be distinguished: the emission of the resonant line at $146.7 \mathrm{~nm}$, the emission of the high vibrational levels of the excimer correlated to the resonant state around $147 \mathrm{~nm}$ and the emission of the high vibrational levels of the excimer correlated to the metastable state around $152 \mathrm{~nm}$ :

$$
\begin{aligned}
& I_{146.7 \mathrm{~nm}}^{1 s t}(t)=Q \frac{\left[\mathrm{Xe}[3 / 2]_{1}^{o}\right]_{0}}{\tau_{a}} \exp \left(\frac{1}{\tau_{a}}-\alpha_{31}[\mathrm{Xe}]^{2} t\right) \\
& I_{147 \mathrm{~nm}}^{1 s t}(t)=Q \frac{\left[\mathrm{Xe}[3 / 2]_{1}^{o}\right]_{0}}{\tau_{0_{u v \gg 0}^{+}}} \frac{1}{\frac{1}{\tau_{0_{u v \gg 0}^{+}}}+\left(\alpha_{t}+\alpha_{r}\right)[\mathrm{Xe}]-\alpha_{31}[\mathrm{Xe}]^{2}} \\
& \times\left[\exp \left[-\left(\frac{1}{\tau_{a}}+\alpha_{31}[\mathrm{Xe}]^{2}\right) t\right]-\exp \left[-\left(\frac{1}{\tau_{0_{u v \gg 0}^{+}}}+\left(\alpha_{t}+\alpha_{r}\right)[\mathrm{Xe}]\right) t\right] 5\right) \\
& I_{152 \mathrm{~nm}}^{1 s t}(t)=Q \frac{\left[\mathrm{Xe}[3 / 2]_{1}^{o}\right]_{0}}{\tau_{1_{u v \sim 0}}} \alpha_{t} \alpha_{31} \alpha_{32}[\mathrm{Xe}]^{5} \times\left[C_{1} \exp \left[-\left(\frac{1}{\tau_{a}}+\alpha_{31}[\mathrm{Xe}]^{2}\right) t\right]\right. \\
& +C_{2} \exp \left[-\left(\frac{1}{\tau_{0_{u v \gg 0}^{+}}}+\left(\alpha_{t}+\alpha_{r}\right)[\mathrm{Xe}]\right) t\right]+C_{3} \exp \left[-\alpha_{32}[\mathrm{Xe}]^{2} t\right] \\
& \left.+C_{4} \exp \left[-\left(\frac{1}{\tau_{1_{u_{v} \gg 0}}}+\alpha_{r}[\mathrm{Xe}]\right) t\right]\right]
\end{aligned}
$$

where $C_{i}$ are constants, some of which are expressed below in equation 20 .

Our experimental device is unable to measure the fast decay frequencies due to the limitation of its time resolution ( $5 \mathrm{~ns}$ ). The radiative decay of high vibrational levels of the $\mathrm{Xe}_{2}\left(\mathrm{~B}_{u}^{+}\right)$excimers cannot be observed. The lifetimes of these vibrational states is about $4 \mathrm{~ns}$ according to Bonifield et al [27]. Life times values reported by Madej et al [34] of high vibrational levels of $\mathrm{Xe}_{2}\left(\mathrm{~A} 1_{u}\right)_{v>0}$ excimers are about a few tens of nanoseconds. The reaction rates $\alpha_{r}$ and $\alpha_{t}$ have been reported by Bonnified et al [27] 
and Ledru et al [14] at room temperature. Their values are close to $\sim 6 \times 10^{-11} \mathrm{~cm}^{3} \mathrm{~s}^{-1}$. Consequently only two decay frequencies can be experimentally observed corresponding to the decay of the resonant state or the metastable state.

In the case of a selective excitation of the metastable state, the intensity of the first continuum can be approximated by:

$$
I^{1 s t}(t)=Q \frac{\left[\mathrm{Xe}[3 / 2]_{1}^{o}\right]_{0} k_{32}[\mathrm{Xe}]^{2}}{1+\tau_{1_{u v \gg 0}}\left(\alpha_{r}[\mathrm{Xe}]-\alpha_{32}[\mathrm{Xe}]^{2}\right)} \exp \left(-\alpha_{32}[\mathrm{Xe}]^{2} t\right)
$$

The components of the different contributions of the first continuum following an excitation of the resonant state, are approximatively:

$$
\begin{aligned}
I_{147 \mathrm{~nm}}^{1 s t}(t)= & Q \frac{\left[\mathrm{Xe}[3 / 2]_{1}^{o}\right]_{0}}{\tau_{a}} \exp \left(\frac{1}{\tau_{a}}-\alpha_{31}[\mathrm{Xe}]^{2} t\right) \\
I_{148 \mathrm{~nm}}^{1 s t}(t)= & Q \frac{\left[\mathrm{Xe}[3 / 2]_{1}^{o}\right]_{0} \alpha_{31}[\mathrm{Xe}]^{2}}{1+\tau_{0_{u v \gg 0}^{+}}\left(\alpha_{t}+\alpha_{r}\right)[\mathrm{Xe}]} \exp \left[-\left(\frac{1}{\tau_{a}}+\alpha_{31}[\mathrm{Xe}]^{2}\right) t\right] \\
I_{152 \mathrm{~nm}}^{1 s t}(t)= & Q \frac{\left[\mathrm{Xe}[3 / 2]_{1}^{o}\right]_{0} \alpha_{t} \alpha_{31} \alpha_{32}[\mathrm{Xe}]^{5}}{\left(1+\tau_{1_{u v \gg 0}} \alpha_{r}[\mathrm{Xe}]\right)\left(\frac{1}{\tau_{0_{u v}^{+}}}+\left(\alpha_{t}+\alpha_{r}\right)[\mathrm{Xe}]\right)\left(\frac{1}{\tau_{a}}+\left(\alpha_{31}-\alpha_{32}\right)[\mathrm{Xe}]^{2}\right)} \\
& \times\left[\exp \left[-\left(\frac{1}{\tau_{a}}+\alpha_{31}[\mathrm{Xe}]^{2}\right) t\right]-\exp \left[-\alpha_{32}[\mathrm{Xe}]^{2} t\right]\right]
\end{aligned}
$$

Therefore, the number of first continuum photons per unit time liable to be recorded with our detection device, after selectively populating the resonant state, corresponds to:

$$
n(t)=A_{2} \exp \left[-\alpha_{32}[\mathrm{Xe}]^{2} t\right]+A_{1} \exp \left[-\left(\frac{1}{\tau_{a}}+\alpha_{31}[\mathrm{Xe}]^{2}\right) t\right]
$$

or, after a selective excitation of the metastable sate:

$$
n(t)=A_{3} \exp \left[-\alpha_{32}[\mathrm{Xe}]^{2} t\right]
$$

The experimental value of the positive amplitude $A_{2}$ increases with increasing number density. The amplitude $A_{1}$ is positive at low number densities and negative above approximatively $2 \times 10^{18} \mathrm{~cm}^{-3}$. Up to this number density, the absolute values of $A_{1}$ and $A_{2}$ are very close and the temperature dependence seems weak. The sum of the amplitudes corresponds to the amplitude of the sum $I_{146.7 \mathrm{~nm}}^{1 s t}(t)+I_{147 \mathrm{~nm}}^{1 s t}(t)$. Therefore the amplitudes of the sum of the components of the first continuum $I_{146.7 \mathrm{~nm}}^{1 s t}(t)+I_{147 \mathrm{~nm}}^{1 s t}(t)$ become weak at high number densities. The emissions of the first continuum arise from the radiative decay of the excimer correlated to the metastable state. The formation of high vibrational levels of the $\mathrm{Xe}_{2}\left(\mathrm{~B}_{u}^{+}\right)_{v \gg 0}$ excimers and the transfer from these excimers to the metastable state via repulsive molecular states seems to be the dominant process of the decay of the resonant state above $2 \times 10^{18} \mathrm{~cm}^{-3}$. Consequently, the emissions of the first continuum peaking at $147 \mathrm{~nm}$ are no more observed in these number density ranges. On the contrary, at low number densities, the amplitude $A_{2}$ vanishes like the component of the first continuum $I_{152 \mathrm{~nm}}^{1 s t}$. The main components are $I_{146.7 \mathrm{~nm}}^{1 s t}+I_{147 \mathrm{~nm}}^{1 s t}$ and the first continuum is peaking around $147 \mathrm{~nm}$. 


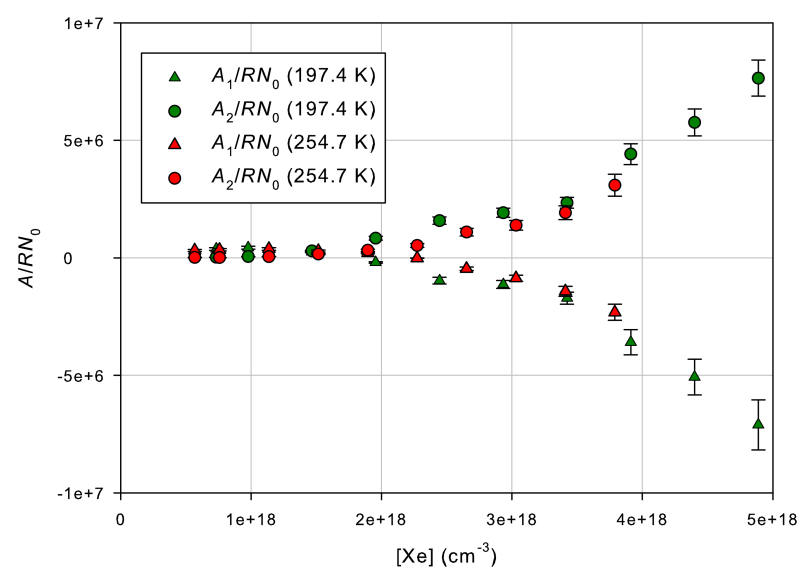

Figure 12. variation of the amplitudes versus xenon pressure for the first continuum $\left(\lambda_{\text {filter }}=148 \mathrm{~nm}, \Delta \lambda=17.5 \mathrm{~nm}\right.$ following selective excitation of $\mathrm{Xe}_{2}\left(\mathrm{~B} 1_{g}\right)$. The amplitudes of the records are divided by the time resolution $R$ of our detection device.

The determination of the reaction rate constant $\alpha_{r}+\alpha_{t}$ requires an accurate determination of the sums of amplitudes $A_{1}+A_{2}$. Unfortunately, the uncertainties and the weak values of the sums of the amplitudes $A_{1}$ and $A_{2}$ with respect to the absolute values of these amplitudes do not allow enough accuracy in the calculations of $\alpha_{r}$ and $\alpha_{t}$ at high number densities. However the variations of the amplitudes against number density can only be explained by assuming that the relaxation and transfer rate constants remains unaffected when the temperature changes. No other behavior versus temperature of these coefficients is reported in literature. Therefore, we are unable to give more detailed explanations and calculations of the temperature influence on these coefficient $\alpha_{t}$ and $\alpha_{r}$.

Temperature variations do not modify the mechanisms of decay of the resonant state and the kinetic model suitable at room temperature remains relevant in the range of 200 to $300 \mathrm{~K}$. The measurements of the decay frequencies of the resonant or the metastable state clearly show the temperature dependence of the three-body rate constants of formation of excimers. Figure 13 represents these temperature dependences. The experimental data can be fitted by least-squares to the function $\alpha=\alpha_{0} T^{\beta}$ often used in collision theories [26].

The fitting procedure yields the following three-body reaction rates in units of $\mathrm{cm}^{-6} \cdot \mathrm{s}^{-1}$ :

$$
\begin{aligned}
& \alpha_{31}=3.90( \pm 0.19) \times 10^{-27} T^{-1.78( \pm 0.09)} \\
& \alpha_{32}=1.34( \pm 0.08) \times 10^{-27} T^{-1.70( \pm 0.02)}
\end{aligned}
$$

or in units of $\operatorname{Torr}^{-2} \cdot \mathrm{s}^{-1}$ :

$$
\begin{aligned}
& k_{31}=3.64( \pm 0.18) \times 10^{11} T^{-3.78( \pm 0.09)} \\
& k_{32}=1.25( \pm 0.07) \times 10^{11} T^{-3.70( \pm 0.02)}
\end{aligned}
$$




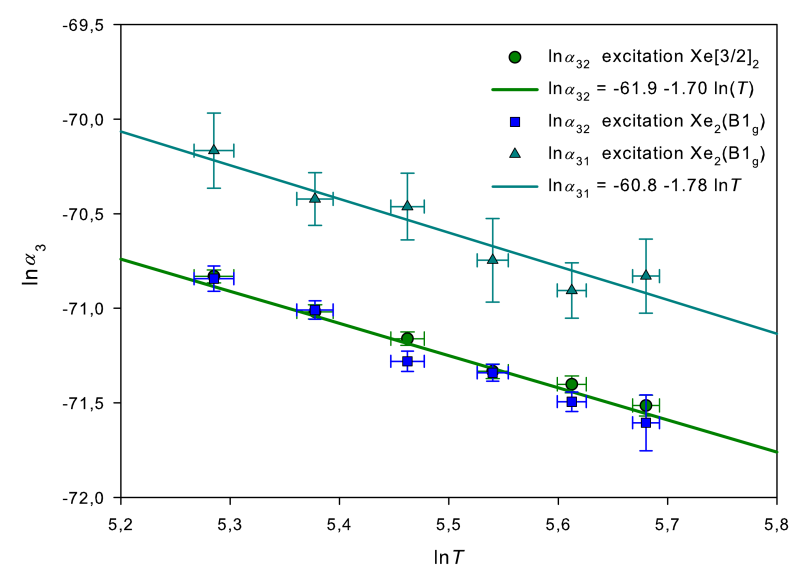

Figure 13. Logarithm of the tree-body rate constants $\alpha_{31}$ and $\alpha_{32}$ versus the logarithm of the temperature. Selective excitation of $\mathrm{Xe}_{2}\left(\mathrm{~B} 1_{g}\right)$ or Xe6s $[3 / 2]_{2}^{o}$ states.

The three-body coefficient for excimer formation of xenon increases with decreasing temperature. This was already reported by Wieme and Lenaerts [26] in argon, krypton and xenon and by Turner [25] in krypton. In these studies, the decay of the VUV continuum was measured in an afterglow pulsed dc discharge. The temperature dependence of the three-body rate $\alpha_{32}$ reported by Wieme and Lenaerts [26] for the range from $200 \mathrm{~K}$ to $400 \mathrm{~K}$ is:

$$
\alpha_{32}=1.70( \pm 0.20) \times 10^{-30} T^{-0.66( \pm 0.10)}
$$

Around the room temperature the values obtained by Wieme and Lenaerts [26] are close to ours. At room temperature, all the determinations of $\alpha_{32}$ found in the literature are around $8 \times 10^{-32} \mathrm{~cm}^{6} \mathrm{~s}^{-1}[14,17,20,22,24,35]$. For temperatures lower than $273 \mathrm{~K}$, only one value was measured by these authors at $190 \mathrm{~K}$ and this temperature corresponds to the upper relative variation of the rate constant. Furthermore, these authors consider that the decay of the metastable state can be thought as a sum of two collision processes: two-body and three-body collisions. This was not found in our experiments using selective excitation of the metastable state or the resonant state. Only three-body collisions lead to the formation of xenon excimers as already reported by recents works. The discrepancy between our results and the temperature dependence law found by Wieme and Lenaerts [26] in xenon can be explained by the time resolution of their measurement system $(0.5 \mu \mathrm{s})$ and the pulse fall-time of about $(1 \mu \mathrm{s})$ did not allow these authors to measure fast decays at low temperatures. Consequently, their values obtained at low temperatures are questionable, although the analytic expression of the variation of $\alpha_{32}=\alpha_{0} T^{\beta}$ remains valid.

The reactions for excimers formation by three-body collisions are:

$$
\begin{aligned}
& \mathrm{Xe} 6 s[3 / 2]_{2}^{o}+\mathrm{Xe}\left({ }^{1} \mathrm{~S}_{0}\right)+\mathrm{Xe}\left({ }^{1} \mathrm{~S}_{0}\right) \rightleftharpoons \mathrm{Xe}_{2}\left(\mathrm{~A} 1_{u v \gg 0}\right)+\mathrm{Xe}\left({ }^{1} \mathrm{~S}_{0}\right) \\
& \mathrm{Xe} 6 s[3 / 2]_{1}^{o}+\mathrm{Xe}\left({ }^{1} \mathrm{~S}_{0}\right)+\mathrm{Xe}\left({ }^{1} \mathrm{~S}_{0}\right) \rightleftharpoons \mathrm{Xe}_{2}\left(\mathrm{~B} 0_{u v \gg 0}^{+}\right)+\mathrm{Xe}\left({ }^{1} \mathrm{~S}_{0}\right)
\end{aligned}
$$


These reactions are assumed to proceed via sequential two-body collision mechanisms $[26,36-38]$. First, a collision between an excited atom Xe* (e. g. Xe6s $[3 / 2]_{2}^{o}$ or Xe6s $\left.[3 / 2]_{1}^{o}\right)$ and a ground state atom (e.g. Xe $\left.\left({ }^{1} \mathrm{~S}_{0}\right)\right)$ forms an intermediate $\mathrm{Xe}_{2}^{* *}$ in an unstable continuum excimer state [36]. The lifetime of the intermediate $\mathrm{Xe}_{2}^{* *}$ is very short, limited to the collision time. The total energy of the intermediate, also called a quasi-molecule according to Janssens et al [36], is the sum of the atomic energy of the excited atomic species and $2 k_{B} T$, which is the relative kinetic energy at large internuclear distances. During its lifetime, the quasi-molecule can interact with a thirdbody (e. g. Xe $\left.\left({ }^{1} S_{0}\right)\right)$ that can carry away the excess of energy and stabilize excimers in a bound vibrational level $\mathrm{Xe}_{2}^{*}$. The two collisional mechanisms can be summarized by the reactions :

$$
\begin{aligned}
& \mathrm{Xe}^{*}+\mathrm{Xe}\left({ }^{1} \mathrm{~S}_{0}\right) \rightleftharpoons \mathrm{Xe}_{2}^{* *} \\
& \mathrm{Xe}_{2}^{* *}+\mathrm{Xe}\left({ }^{1} \mathrm{~S}_{0}\right) \rightleftharpoons \mathrm{Xe}_{2}^{*}+\mathrm{Xe}\left({ }^{1} \mathrm{~S}_{0}\right)
\end{aligned}
$$

If we assume that the sum of these reactions satisfy detailed balance, the rate constants can be fitted by an Arrhenius function [26] (figure 14):

$$
\alpha=C \exp \left(-\frac{E_{a}}{T}\right)
$$

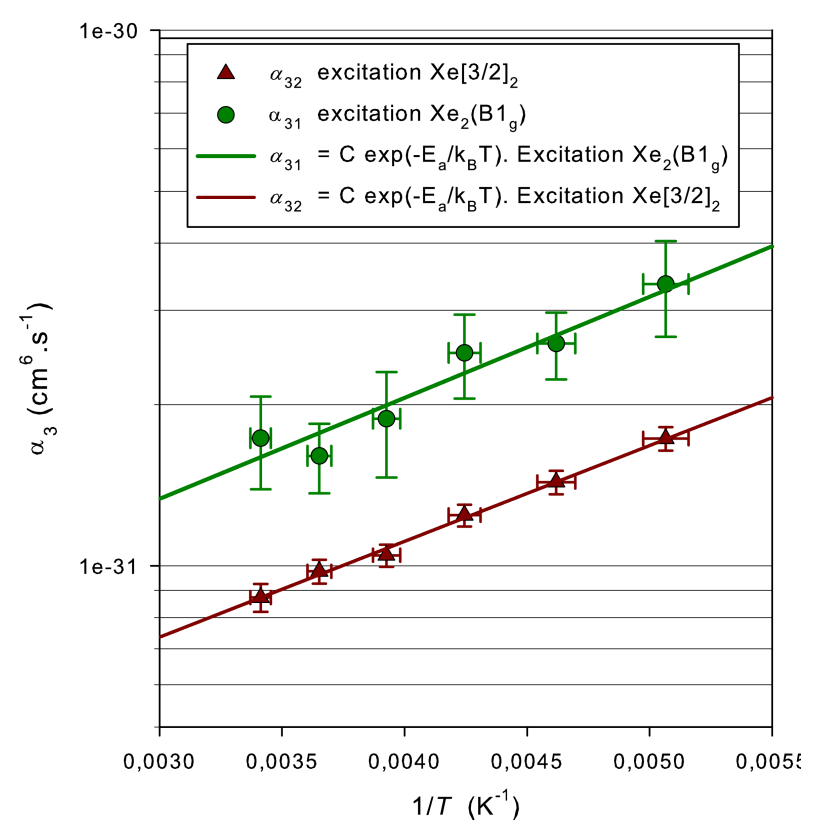

Figure 14. Arrhenius plot giving the three-body rate constants $\alpha_{31}$ and $\alpha_{32}$ vs $T^{-1}$.

The corresponding activation energies, $E_{a 1}$ and $E_{a 2}$ are deduced from the experimental data for the formation of respectively the $\mathrm{Xe}_{2}\left(\mathrm{~A} 1_{u}\right)$ or $\mathrm{Xe}_{2}\left(\mathrm{~B} 0_{u}^{+}\right)$ excimers:

$$
\begin{aligned}
& E_{a 1}=(-301 \pm 20) \mathrm{cm}^{-1} \\
& E_{a 2}=(-286 \pm 13) \mathrm{cm}^{-1}
\end{aligned}
$$


Negative activation energy were also reported by Wieme and Lenaerts [26] for argon, krypton and xenon. For the formation of $\mathrm{Xe}_{2}\left(\mathrm{~A} 1_{u}\right)$ excimer, they found $E_{a 2}=$ $-130 \mathrm{~cm}^{-1}$. According to these authors, positive values of $E_{a}$ correspond to the height of the hump in the excimer potential energy curves and the negative values of $E_{a}$ imply the absence of a potential hump at large internuclear distances of the excimers and suggest that the excimers are formed in high vibrational levels close to the dissociation limit and then, stabilized by collisions with ground state atoms. Our results are consistent with the potential energy curves of $\mathrm{Xe}_{2}\left(\mathrm{~A}_{1}\right)$ and $\mathrm{Xe}_{2}\left(\mathrm{~B}_{u}^{+}\right)$calculated by Jonin et al $[32,33]$. These authors do not report potential hump for the potential anergy curves of the lowest xenon excimer states $\mathrm{A} 1_{u}, \mathrm{~A} 0_{u}^{-}$and $\mathrm{B} 0_{u}^{+}$. The reverse reaction of stabilization leads to the dissociation of the quasi-molecule $\mathrm{Xe}_{2}^{* *}$ into resonant or metastable atomic state. The dissociation increases with increasing temperature and the probability for a the quasi-molecule to be stabilized thereof decreases. The decrease of the rate constants of formation of excimer with increasing temperature shows the importance of the dissociation reaction where atoms with higher kinetic energy are involved.

For our experiments dealing with selective excitation of neutral gases, the gas temperature hardly varies with increasing pressure. Consequently, excimer formation is much favored at higher pressures. However, as far as excilamps are concerned, particularly those working with high specific power, the increase of pressure may cause a severe rise of the operating gas temperature. Subsequently, in such DBDs, excimer formation may be altered, suggesting that such high power $\mathrm{Xe}_{2}$ excilamps need to be cooled in order to maintain high VUV efficiencies. Indeed, 400 Torr pure xenon multifilamentary excilamps actually devoted to water decontamination need to be cooled [39] in order to ensure good operating conditions. These results are in good agreement with the results reported in a previous paper [35]. We found that the maximum efficiency of non-cooled monofilamentary DBD is achieved around 200 Torr

\section{Conclusion}

The first continuum luminescence decay kinetics of xenon was studied under twophoton laser excitation in a temperature range between $200 \mathrm{~K}$ and room temperature. This selective excitation led to initially populate exclusively either the resonant state $\mathrm{Xe} 6 s[3 / 2]_{1}^{o}$ or the metastable stateXe6s $[3 / 2]_{2}^{o}$. The decay and formation mechanisms of xenon excimers are similar over the whole temperature range. Formation of excimers occurs by three-body collisions. The three-body coefficients for collisional decay of the resonant state or the metastable state were determined as a function of the temperature and a good agreement was found at room temperature with the literature values. The three-body rate constants expressed in $\mathrm{cm}^{-6} \cdot \mathrm{s}^{-1}$, were found to vary approximately as $T^{-1,7}$ for the formation of excimers correlated to the first resonant or metastable state. This variation law is reported for the first time under selective excitation. 
This study shows that the use of room temperature values of rate coefficients of formation of excimers when analyzing experiment and theoretical prediction or modeling, are not suitable if the gas temperature undergoes significant changes.

In the temperature range between $200 \mathrm{~K}$ and $300 \mathrm{~K}$, no transfer from the metastable state to the resonant state was observed. On the contrary, the transfer from the excimer correlated to the resonant state to the metastable state via dissociative states correlated to the metastable was found to be more efficient at low temperatures. The increase of the transfer rate constant with decreasing temperature explains the shift of the first continuum at $152 \mathrm{~nm}$ at low temperatures following selective excitation of the resonant state. Unfortunately, the behavior of the transfer coefficient versus temperature have not been obtained with enough accuracy. To our knowledge, the theoretical calculations concerning this collisional transfer in rare gases are nonexistent and do not allow us to interpret the present results.

Wieme and Lernaerts [26] have determined the three-body collisional decay rate constant of the first metastable state of argon, krypton and xenon. Our results differ from their's at low temperatures (around $200 \mathrm{~K}$ ). Recent measurements under using TALIF techniques and for which preliminary results will be published soon, show that the three-body collisional decay rate constant of the first metastable state of krypton varies as $T^{-1,6}$. It might be interesting to carry out a similar analysis in neon and argon.

\section{References}

[1] R P Mildren and R J Carman. Enhanced performance of a dielectric barrier discharge lamp using short-pulsed excitation. J. Phys. D., 34:L1-L6, 2001.

[2] K Vollkommer and L Hizschle. In G Babucke, editor, Proceedings of the eighth international symposium on the science and technology of light sources, pages 51-60, Greifswald, Germany, August 1998.

[3] N Merbahi, G Ledru, N Sewraj, and F Marchal. Electrical behavior and vacuum ultraviolet radiation efficiency of monofilamentary xenon dielectric barrier discharges. J. Appl. Phys., 101:123309-123309.9, 2007.

[4] T Oppenlander. Mercury-free sources of VUV/UV radiation: application of modern excimer lamps (excilamps) for water and air treatment. J. Environ. Eng. Sci., 6:253-64, 2007.

[5] E A Sosnin, T Oppenander, and Tarasenko V F. Applications of capacitive and barrier discharge excilamps in photoscience. Journal of Photochemistry and Photobiology C: Photochemistry Reviews, 7:145-63, 2006.

[6] K H Becker, U Kogelschatz, K H Schoenbach, and R J Barker. Non-Equilibrium Air Plasmas at Atmospheric Pressure Spectra of Diatomic Molecules. Institute of Physics Publishing, Bristol, 2005.

[7] B Eliasson and B Gellert. Investigation of resonance and excimer radiation from a dielectric barrier discharge in mixtures of mercury and the rare gases. J. appl. Phys., 68:2026-37, 1990.

[8] B Eliasson and U Kogelschatz. Nonequilibrium volume plasma chemical processing. IEEE Trans. Plasma Sci., 19:1063-77, 1991.

[9] B Eliasson and U Kogelschatz. UV excimer radiation from dielectric-barrier discharges. Appl. Phys. B, 46:299-303, 1988.

[10] A Habachi and K H Schoenbach. Emission of excimer radiation from direct current, high-pressure hollow cathode discharges. Appl. Phys.Lett., 72:22-4, 1986. 
[11] U Kogelschatz. Silent discharge driven excimer UV sources and their applications. Appl. Surf. Sci., 54:410-23, 1992.

[12] M Laroussi, F C Dobbs, Z Wei, M A Doblin, L G Ball, K R Moreira, F F Dyer, and J P Richardson. Decontamination of water by excimer uv radiation. IEEE Trans. Plasma Sci., 30:1501-3, 2002.

[13] F Marchal, N Merbahi, Ledru, JP Gardou, and N Sewraj. The study of vuv emissions of $\mathrm{A} r_{2}^{*}$ excimers using three-photon absorption laser-induced fluorescence. J. Phys. B: At. Mol. Phys., 42(1):015201, 015201.10, 2009.

[14] G Ledru, F Marchal, N Sewraj, Y Salamero, and P Millet. Comparative study of the formation and decay of xenon excimers following selective excitation of the $5 p^{5} 6 s$ states: spectroscopic and kinetic analysis. J. Phys. B: At. Mol. Phys., 39:2031-57, 2006.

[15] G Ledru, F Marchal, N Merbahi, J P Gardou, and N Sewraj. Study of the formation and decay of $\mathrm{KrXe}^{*}$ excimers at room temperature following selective excitation of the xenon $6 \mathrm{~s}$ states. $J$. Phys. B: At. Mol. Phys., 40:1651-74, 2007.

[16] F Marchal, P Berejny, N Sewraj, Y Salamero, and P Millet. Energy transfers in Kr-Xe mixtures following selective multiphotonic excitation of $\operatorname{Kr}\left({ }^{3} \mathrm{P}_{1}\right)$. Temporal analysis in $\mathrm{Kr}$-Xe mixtures. J. Phys. B: At. Mol. Phys., 37:1279-1304, 2004.

[17] N Sewraj, J P Gardou, Y Salamero, and P Millet. Radiation trapping of the ${ }^{3} \mathrm{P}_{1}{ }^{-1} \mathrm{~S}_{0}$ resonant transitions of xenon and krypton in Xe-Kr, Xe-Ar and $\mathrm{Kr}-\mathrm{Ar}$ mixtures: Kinetic analysis and determination of van der Waals broadening coefficients. Physical Review A, 62:1-21, 2000.

[18] P Moutard, P Laporte, J L Subtil, N Damany, and H Damany. Pressure effects on kinetics and decay processes in argon under selective photoexcitation. J. Chem. Phys., 87:4576-88, 1987.

[19] A Barbet, N Sadeghi, and J C Pebay-Peyroula. Decay of metastable xenon atoms $\mathrm{Xe}^{*}\left({ }^{3} \mathrm{P}_{2}\right)$ in a xenon afterglow. J. Phys. B :Atom. Molec. Phys., 8:1776, 1975.

[20] P K Leichner, K F Palmer, J D Cook, and M Thieneman. 2-body and 3-body collision coefficient for $\mathrm{Xe}\left({ }^{3} \mathrm{P}_{1}\right)$ and $\mathrm{Xe}\left({ }^{3} \mathrm{P}_{2}\right)$ atoms and radative lifetime of $\mathrm{Xe}_{2}\left(1_{u}\right)$ molecule. Phys. Rev. A, 13:1787, 1976.

[21] P Millet, A Birot, H Brunet, J Galy, B Pons-Germain, and J L Teyssier. Time resolved study of the UV and near UV continuums of xenon. J. Chem. Phys., 69:92-97, 1978.

[22] Y Salamero, A Birot, H Brunet, J Galy, and P Millet. Kinetic study of the VUV xenon emissions using selective multiphoton excitation. J. Chem. Phys., 80:4774-80, 1984.

[23] W Wieme, M Vanmarcke, and $\mathrm{W}$ Bruynooghe. Radiative and collisional de-excitation of ${ }^{1} \mathrm{P}_{1}$ and ${ }^{3} \mathrm{P}_{1}$ resonance states in xenon. J. Phys., 40:C7-3, 1979.

[24] H D Wenck, S S Hasnain, M M Nikitin, Sommer K, Zimmerer G., and Haaks D. Time and spectrally resolved fluorescence of $\mathrm{Xe}_{2}$ molecules excited with synchrotron radiation. Chem. Phys. Lett., 66:138-143, 1979.

[25] R. Turner. Decay of excited species in a pulsed discharge in krypton. Phys. Rev., 158(1):121-129, 1967.

[26] W Wieme and J Lenaerts. Excimer formation in argon, krypton ans xenon discharge afterglows between 200 and $400 \mathrm{k}$. J. Chem. Phys., 1:483-493, 1981.

[27] T D Bonifield, F H K Rambow, G K Walters, M V McCusker, D C Lorents, and R A Gutcheck. Time resolved spectroscopy of xenon excimers excited by synchrotron radiation. J. Chem. Phys., 72:2914-24, 1980.

[28] F Marchal. Thèse de l'université no 2486. PhD thesis, Université Paul Sabatier, Toulouse III, 1996.

[29] ISO/IEC Guide 98:1995, Guide to the expression of uncertainty in measurement (GUM). ISO, Geneva, Switzerland, 1995.

[30] W Gornik, E Matthias, and D Schmidt. 2-photon excitation of the lowest g-states in $\mathrm{Xe}_{2}^{*} . J$. Phys. B, 15(19):3413-3422, 1982.

[31] P Moutard, P Laporte, J L Subtil, N Damany, and H Damany. Pressure effects on kinetics and decay processes in xenon after selective photoexcitation. J. Chem. Phys., 88:7485-7500, 1988.

[32] C Jonin and F Spiegelmann. Pseudopotential hole-particle formalism for excitations in xenon 
molecules and clusters. ii. the electronic structure of $\mathrm{Xe}_{2}$. J. Chem. Phys., 117:3059-3073, 2002.

[33] C Jonin, P Laporte, and F Spiegelmann. Pseudopotential hole-particle formalism for excitations in xenon molecules and clusters. i. theory, atomic and molecular tests. J. Chem. Phys., 117:30493058, 2002.

[34] A A Madej, P R Herman, and Stoicheff B P. Radiative lifetimes of argon molecules and dependence on internuclear distance. Phys. Rev. Lett., 57:1574-6, 1986.

[35] N Sewraj, N Merbahi, F Marchal, G Ledru, and J P Gardou. Vuv spectroscopy and post-discharge kinetic analysis of a pure xenon mono-filamentary dielectric barrier discharge (mf-dbd). Journal of Physics D: Applied Physics, 42(4):045206, 2009.

[36] H Janssens, M Vanmarcke, E Desoppere, J Lenaerts, R Bouciqué, and W Wieme. Quasi-classical theory of 2-body and 3-body collisions in rare-gases, with application to krypton excimer formation. J. Chem. Phys., 86:4935-4944, 1987.

[37] Russell T Pack, Robert B. Walker, and Brian K. Kendrick. Three-body collision contributions to recombination and collision-induced dissociation. i. cross sections. The Journal of Chemical Physics, 109(16):6701-6713, 1998.

[38] Russell T Pack, Robert B. Walker, and Brian K. Kendrick. Three-body collision contributions to recombination and collision-induced dissociation. ii. kinetics. The Journal of Chemical Physics, 109(16):6714-6724, 1998.

[39] Benoit-Marquié, F., Wilkenhöner, U., Braun, A. M., Oliveros, E., and Maurette, M.-T. Lampes à excimère au xe et xecl adaptées à la photochimie, applications à la dégradation de matière organique en phase gaz. J. Phys. IV France, 09:113-116, 1999. 